OPEN ACCESS

Edited by:

Sherven Sharma,

VA Greater Los Angeles Healthcare

System (NHA), USA

Reviewed by:

Kia Joo Puan,

Singapore Immunology Network

(A*STAR), Singapore

Bruce Loveland,

Burnet Institute, Australia

${ }^{*}$ Correspondence:

Nor Adzimah Johdi

adzimah@ppukm.ukm.edu.my

Specialty section: This article was submitted

to Cancer Immunity and Immunotherapy,

a section of the journal

Frontiers in Immunology

Received: 28 September 2016

Accepted: 10 May 2017

Published: 30 May 2017

Citation:

Johdi NA, Ait-Tahar K, Sagap I and Jamal R (2017) Molecular Signatures of Human Regulatory T Cells in Colorectal Cancer and Polyps.

Front. Immunol. 8:620.

doi: 10.3389/fimmu.2017.00620

\section{Molecular Signatures of Human Regulatory T Cells in Colorectal Cancer and Polyps}

\author{
Nor Adzimah Johdi ${ }^{1 *}$, Kamel Ait-Tahar ${ }^{1}$, Ismail Sagap ${ }^{2}$ and Rahman Jamal ${ }^{1}$ \\ 1 UKM Medical Molecular Biology Institute, Universiti Kebangsaan Malaysia, Cheras, Kuala Lumpur, Malaysia, \\ ${ }^{2}$ Faculty of Medicine, Department of Surgery, Universiti Kebangsaan Malaysia, Cheras, Kuala Lumpur, Malaysia
}

Regulatory $\mathrm{T}$ cells (Tregs), a subset of $\mathrm{CD}^{+}$or $\mathrm{CD}^{+} \mathrm{T}$ cells, play a pivotal role in regulating immune homeostasis. An increase in Tregs was reported in many tumors to be associated with immune suppression and evasion in cancer patients. Despite the importance of Tregs, the molecular signatures that contributed to their pathophysiological relevance remain poorly understood and controversial. In this study, we explored the gene expression profiles in Tregs derived from patients with colorectal cancer [colorectal carcinoma (CRC), $n=15$ ], colorectal polyps (P, $n=15)$, and in healthy volunteers $(\mathrm{N}, n=15)$. Tregs were analyzed using $\mathrm{CD}^{+}{ }^{+} \mathrm{CD} 25^{+} \mathrm{CD} 127^{\text {low } F o x P} 3^{+}$antibody markers. Gene expression profiling analysis leads to the identification of 61 and 66 immune-related genes in Tregs derived from $\mathrm{CRC}$ and $\mathrm{P}$ patients, respectively, but not in N-derived Treg samples. Of these, 30 genes were differentially expressed both in CRC- and P-derived Tregs when compared to N-derived Tregs. Most of the identified genes were involved in cytokine/chemokine mediators of inflammation, chemokine receptor, lymphocyte activation, and T cell receptor (TCR) signaling pathways. This study highlights some of the molecular signatures that may affect Tregs' expansion and possible suppression of function in cancer development. Our findings may provide a better understanding of the immunomodulatory nature of Tregs and could, therefore, open up new avenues in immunotherapy.

Keywords: regulatory $\mathrm{T}$ cells, colorectal cancer, gene expression, immune suppression, interleukin

\section{INTRODUCTION}

Regulatory T cells (Tregs) are suppressor cells that play a pivotal role in regulating immune hemostasis and immunological tolerance to self (1). Tregs are present in low numbers (1-2\% of lymphocytes) within both $\mathrm{CD}^{+}$and $\mathrm{CD} 8^{+}$populations $(2,3)$. Their main function is to prevent inappropriate immune responses by suppressing immune effector cells. This is useful for maintaining immune hemostasis in autoreactivity, severe inflammation, and transplantation in patients. However, excessive Tregs' oversuppression in cancers and tumor environment may lead to undesirable immune tolerance and evasion. The frequencies of Tregs in peripheral blood, lymphoid tissues, and tumor microenvironment have been investigated in many different types of cancers including liver, breast, renal, leukemia, and gastric cancers and were associated with cancer progression and poor prognosis suggesting their critical role in tumor development (4-8). However, contradictory reports on their role exist in the colon, gastric, and head and neck cancers (9-11). The discrepancies could be due to unstandardized antibody markers used in different laboratories and varying terminologies used to 
describe different subpopulations of Tregs (12). This complicates direct comparison between studies. Despite the availability of many markers associated with Tregs, the most prominent Tregs are $\mathrm{CD}^{+} \mathrm{CD} 25^{+} \mathrm{CD} 127^{\text {low } F o x P} 3^{+}(13-15)$. At the functional level, cytokines produced by Tregs such as elevated levels of IL-10 $(16,17)$ and TGF- $\beta(18)$ are also widely used. Various mechanisms contribute to the elevated numbers and suppressive function of Tregs in cancer. However, there are a limited number of studies describing the molecular signatures that may contribute to the underlying Tregs-mediated tolerance and suppression in cancer development.

Colorectal carcinoma (CRC) is the third most common cancer worldwide with an estimated number of 1.4 million $(9.7 \%)$ cases in 2012 (19). In Malaysia, 2,246 CRC cases (12.3\%) were reported in 2011 (20). It is widely recognized that genetic factors play important roles in the pathogenesis of CRC. However, evading immune surveillance is recognized as an emerging hallmark in cancer progression (21). There is considerable evidence to suggest that the immune system plays a protective role in tumorigenesis (22-24). Correlation between serrated polyps and colorectal neoplasia has been largely reported (25-27). Approximately 15-20\% of all sporadic CRCs arise via the serrated pathway, in which serrated polyps may be the precursor lesions $(28,29)$. Serrated polyps are classified pathologically according to the World Health Organization criteria as hyperplastic polyps (HPs), sessile serrated adenoma/polyps with or without cytological dysplasia, and traditional serrated adenomas (30). In the context of CRC progression, Tregs' frequencies and function may be important because high frequencies of Tregs might favor CRC and polyps' growth or development and influence the course of the disease through enhancing suppression of antitumor immunity. Thus, it is interesting to investigate the molecular signatures of Tregs in CRC and polyps and possible correlation with Tregs influences the disease development.

In this study, we explored the gene expression profiles in $\mathrm{CD} 4{ }^{+} \mathrm{CD} 25^{+} \mathrm{CD} 127^{\text {low }}$ FoxP $3{ }^{+}$Tregs derived from CRC, $\mathrm{P}$, and $\mathrm{N}$ samples in order to investigate the molecular signatures that may influence cancer development. We identified a number of differentially expressed Treg transcripts derived from CRC and P patients. We suggest these genes to be relevant for Tregs' general function. Other transcripts were identified to differ among these groups and might give rise to their phenotypic differentiation. These could potentially be used as biomarkers to discriminate Tregs derived from CRC and P patients.

\section{MATERIALS AND METHODS}

\section{Patients and Healthy Volunteers}

Ethics approval was obtained from the UKM Research Ethics Committee (reference number UKM 1.5.3.5/244/FRGS/2/2013/ SKK01/UKM/03/3). Ten to twelve milliliters of peripheral blood were collected in BD Vacutainer ${ }^{\circledR}$ Heparin Tubes (Becton Dickinson) from 15 healthy volunteers (N), 15 patients with colorectal polyps (P), and 15 CRC patients who were diagnosed in UKM Medical Center, Kuala Lumpur (UKMMC) from 2014 to 2015 . N samples were used as a control and classified as the participants who went through endoscopy as part of their annual health screening and were diagnosed as normal. $\mathrm{P}$ samples were those with primary polyps including serrated adenoma, adenoma polyps, and dysplasia. The HPs were not included in the samples. For the CRC cases, the samples were collected from the Dukes' B and Dukes' C stage. Both groups of patients with CRC and $\mathrm{P}$ were histologically confirmed, primary diagnosed, and neither received any form of treatments prior to blood sample collection. The histological stage of the tumor was determined according to the Duke's staging system. Data including patient clinical history, age, gender, colorectal polyp's classification, and tumor staging are summarized in Table 1. None of the donors suffered from allergies, autoimmune diseases, and were free from acute or chronic infections. Patients who underwent neoadjuvant treatment or resection were excluded from the study.

\section{Lymphocyte Isolation}

Peripheral blood mononuclear cells (PBMCs) were isolated by the Ficoll/Paque ${ }^{\mathrm{TM}}$ PLUS density gradient centrifugation method (GE Healthcare Life Sciences) as recommended by the manufacturer. PBMCs were counted and frozen instantly in liquid nitrogen until analyzed.

\section{Antibodies and FACS Analysis}

All the antibodies used in this study were purchased from BD Biosciences unless stated otherwise. Tregs were stained using anti-CD4 (-PerCP-Cy 5.5, clone SK3), anti-CD25 (-PE, clone 2A3), anti-CD127 (-Alexa 647, clone HIL-7R-M21), and antiFoxP3 (-Alexa 488, clone 259D/C7) as recommended in the manufacturer's protocol. A total of $1 \times 10^{6}$ cells were incubated with $10-20 \mu \mathrm{l}$ of the fluorochrome-labeled antibodies in the dark at room temperature for $30 \mathrm{~min}$, washed twice, and analyzed on the flow cytometer. The stained PBMCs were loaded onto BD FACSAria $^{\mathrm{TM}}$ II system (BD Biosciences) and analyzed to confirm the presence of $\mathrm{CD} 4^{+} \mathrm{CD} 25^{+} \mathrm{CD} 127^{\text {low }} \mathrm{FoxP} 3^{+}$(Tregs) and $\mathrm{CD} 4{ }^{+} \mathrm{CD} 25^{-}$(T responder cells). Cells were analyzed and sorted based on their phenotype to a purity of $>90 \%$. Data were analyzed using BD FACSDiva ${ }^{\mathrm{TM}}$ Software (BD Biosciences). Sorted cells were collected in $12 \mathrm{~mm} \times 75 \mathrm{~mm}$ round-bottom tubes coated

TABLE 1 | Clinical data of the patients enrolled in the study.

\begin{tabular}{lccc}
\hline Variables & N $(\boldsymbol{n}=\mathbf{1 5})$ & $\mathbf{P}(\boldsymbol{n}=\mathbf{1 5})$ & CRC $(\boldsymbol{n}=\mathbf{1 5})$ \\
\hline Age (range) & $55-77$ & $56-80$ & $49-81$ \\
Median & $62 \pm 12$ & $68 \pm 10$ & $72 \pm 11$ \\
Sex & & & \\
Male & 9 & 9 & 10 \\
Female & 6 & 6 & 5 \\
Race & & 5 & 9 \\
Malay & 8 & 10 & 6 \\
Chinese & 7 & & \\
Classification & & 2 & 7 \\
Serrated adenoma & & 13 & \\
Tubular adenoma & & & \\
Dukes' B & & & \\
Dukes' C & & &
\end{tabular}


with human $\mathrm{AB}$ serum (Thermo Fisher Scientific) prior to the addition of Dulbecco's phosphate-buffered saline (Thermo Fisher Scientific) + 1\% Human AB serum (Thermo Fisher Scientific, postsort analysis). Sorted cell populations were centrifuged $(100 \times g, 5 \mathrm{~min})$, the supernatant was carefully removed, and the resulting cell suspensions were divided into three fractions. Fraction 1 was used to determine purity, fraction 2 for FoxP3 staining, and fraction 3 for RNA extraction. Purity was calculated as the number of events in the original sort gate after the exclusion of cell debris. Fraction 2 of the sorted cells was stained for intracellular FoxP3 expression using anti-hFoxP3 (-Alexa 488). This was done on cells that were fixed and permeabilized using FoxP3 staining buffer set (BD Pharmingen ${ }^{\mathrm{TM}}$ ), according to the manufacturer's instructions. This was a postsort analysis to confirm that Treg populations express FoxP3 ${ }^{+}$phenotype.

\section{RNA Extraction, Quantification, and Microarray Analysis}

Total RNA was extracted from $2 \times 10^{5}$ Tregs using RNeasy micro kit (Qiagen). Quality and integrity of the total RNA were quantified on Agilent 2100 Bioanalyzer (Agilent Technologies). Only those RNA samples with RIN number of $\geq 7$ and of good integrity were used in the microarray analysis. Total RNA (100 ng) was then reverse transcribed and the single-stranded cDNA (sscDNA) was amplified using the WT-Amplification Kit Module (Affymetrix). The purified sscDNA (5.5-15.0 $\mu \mathrm{g}$ ) was subsequently fragmented and labeled using the GeneChip ${ }^{\circledR}$ WT Terminal Labeling Kit (Affymetrix). Labeled cDNA $(3.5 \mu \mathrm{g})$ was then hybridized to the GeneChip ${ }^{\circledR}$ Human Gene 2.0 ST array (Affymetrix) using the GeneChip ${ }^{\circledR}$ Hybridization Oven 640 (Affymetrix) at 60 rotations per minute at $45^{\circ} \mathrm{C}$ for $16 \mathrm{~h}$. After hybridization, the arrays were washed and stained according to the manufacturer's protocol using a GeneChip ${ }^{\circledR}$ Fluidics Station 450 (Affymetrix). The arrays were scanned using the GeneChip ${ }^{\circledR}$ Scanner 3000 (Affymetrix).

\section{Real-time Quantitative Reverse Transcription PCR (RT-qPCR)}

Validation of differentially regulated target genes identified by expression array was performed using RT-qPCR. The samples were the same CRC, $\mathrm{P}$, and $\mathrm{N}$ samples used for transcriptomic profiling. Random primed cDNA was prepared from total RNA using a high capacity RNA to cDNA kit (Thermo Fisher Scientific). Relative gene expression analysis was carried out using SYBR Green on a 7500 Fast Real-Time PCR system (Thermo Fisher Scientific). Gene-specific primer pairs for qPCR were selected from Primer Bank 25 and listed in Table 2. GAPDH gene was used as an internal control. Results were analyzed using a 7500 Fast Real-Time PCR system software (Thermo Fisher Scientific). Relative mRNA levels were normalized to GAPDH as an internal control gene.

\section{Statistical Analysis}

Microarray data analyses were carried out using Expression and Transcriptome Analysis Console (Affymetrix). Data normalization based on median signal intensities was qualified and
TABLE 2 | List of primers for real-time quantitative reverse transcription PCR.

\begin{tabular}{lll}
\hline Gene & Forward primer & Reverse primer \\
\hline CCR4 & AGAAGGCATCAAGGCATTGG & ACACATCAGTCATGGACCTGAG \\
CXCL10 & GTGGCATTCAAGGAGTACCTC & TGATGGCCTTCGATCTGGATT \\
CCR1 & CCTGCTGACGATTGACAGGTA & TCTCGTAGGCTTCGTGAGGA \\
CCR2 & TACGGTGCTCCCTGTCATAAA & TAAGATGAGGACGACCAGCAT \\
CCR7 & AAGCGATGCGATGCTCTCTC & TTGCGCTCAAAGTGCGTG \\
CCL1 & CTCATTGCGGAGCAAGAGAT & GCCTCTGAACCCATCCAACTG \\
TRAJ1 & GAGGAGGAGAAACTAAGGGATT & CCGAGGCTTAGTGAGCATC \\
TRGJP2 & GTCATGAGGATCAGAAGGTTGA & CCAGGCGAAGTACTATGAGC \\
IL10RA & GAGATCCACAATGGCTTCATCC & TTCTCCAGAGGTTAGGAGGCT \\
GAPDH & TGCACCACCAACTGCTTAGC & GGAAGGCCATGCCAGTGA
\end{tabular}

quantified using Robust Multichip Analysis algorithm, which includes background adjustment, quantile normalization, and summarization. A $\log _{2}$ fold change $>2$ was considered as upregulated genes and $\log _{2}$ fold change $<-2$ as downregulated genes. Statistical significance was calculated by one-way ANOVA and false discovery rate (FDR) correction (adjust $p$-value based on Benjamin-Hochberg Step-Up FDR-controlling Procedure). A $p<0.01$ was considered statistically significant.

\section{RESULTS}

\section{Phenotypic Analysis of Tregs}

Figures $1 \mathrm{~A}-\mathrm{C}$ show the gating strategy of $\mathrm{CD} 4^{+} \mathrm{CD} 25^{+} \mathrm{CD} 127^{\text {low }}$ Tregs relative to the $\mathrm{CD} 4{ }^{+} \mathrm{CD} 25^{+} \mathrm{CD} 127^{\text {high }}$ (non-Tregs). The cells were analyzed and sorted from PBMC populations as outlined in the Materials and Methods section. Purity analysis of the fraction 1 postsort $\mathrm{CD} 4^{+} \mathrm{CD} 25^{+} \mathrm{CD} 127^{\text {low }}$ Tregs was performed, and representative data are presented in Figure 1C. The data confirm high purity of more than $90 \%$. The postsorted CD4 ${ }^{+}$ $\mathrm{CD} 25^{+} \mathrm{CD} 127^{\text {low }}$ Treg populations were also stained for FoxP3 expression. Figures 1D,E show a strong shift indicating a strong Foxp 3 expression in these populations. These results support that the isolated $\mathrm{T}$ cells were mostly $\mathrm{CD} 4{ }^{+} \mathrm{CD} 25^{+} \mathrm{CD} 127^{\text {low }}$ Foxp ${ }^{+}$Treg populations.

\section{Analysis of Treg Population}

Regulatory $\mathrm{T}$ cell populations were analyzed and sorted after PBMC treatment as outlined in the Materials and Methods section. The purity of the isolated Tregs was more than $90 \%$ and expressed high levels of FoxP3 protein. A significant increase in Treg frequencies was observed in CRC-derived Tregs $(12.56 \%)$ when compared to P- and N-derived Tregs (2.86 and 1.83\%, respectively) (Figure 2).

\section{Differentially Expressed Genes (DEGs) in $\mathrm{CD}^{+}{ }^{+} \mathrm{CD} 25^{+} \mathrm{CD}_{12} 7^{\text {low }} \mathrm{FoxP}^{+}$Tregs}

In order to clarify the possible role played by Tregs in human CRC development, we performed transcriptional profiling of Tregs to identify candidate genes whose expression levels may differ between CRC, P, and N samples. Principal component analysis and hierarchical clustering clearly segregated the 


\section{A}

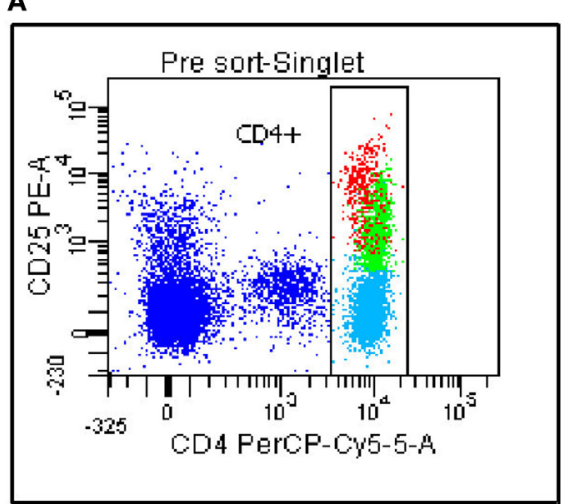

D

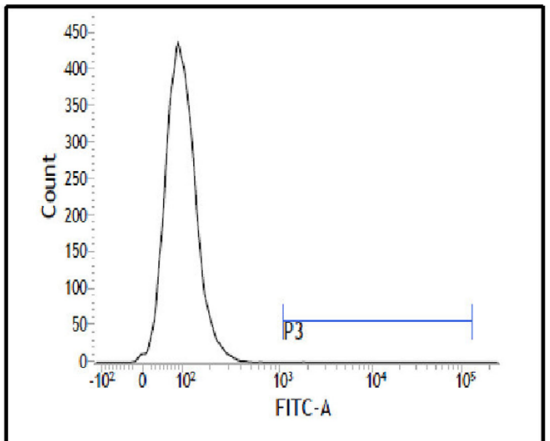

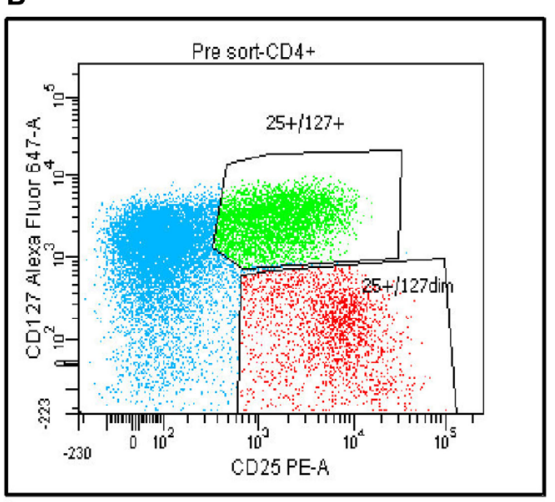

E

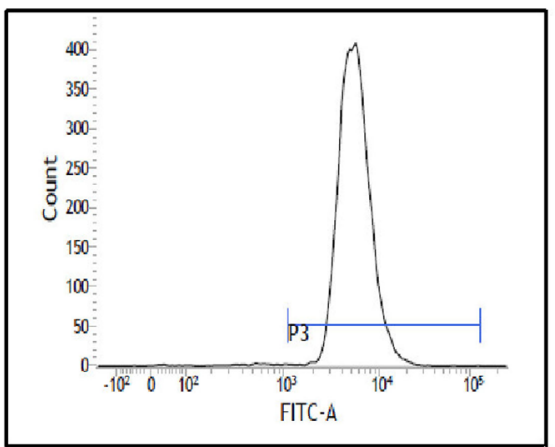

C

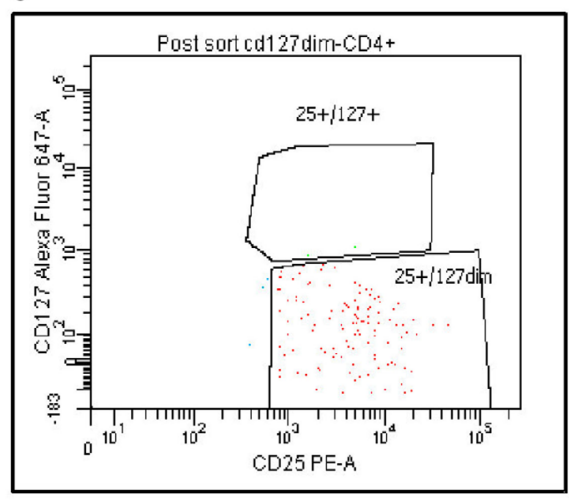

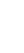

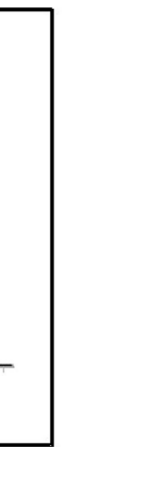

FIGURE 1 | Peripheral blood mononuclear cells from the patients were stained with CD4, CD25, and CD127, and then analyzed on FACS Aria II (BD Biosciences). (A,B) Gating strategies used to sort CD4 ${ }^{+}$CD25 ${ }^{+}$CD127 low Tregs and CD4 ${ }^{+}$CD25 $5^{+}$CD127 high (non-Tregs). (C) Postsort purity determination from fraction 1. (D,E) FoxP3 staining analysis of the postsort CD4 ${ }^{+}$CD2 $5^{+}$CD127 low Tregs. (D) Fluorescence minus one staining. (E) FoxP3 staining on postsorted cells.

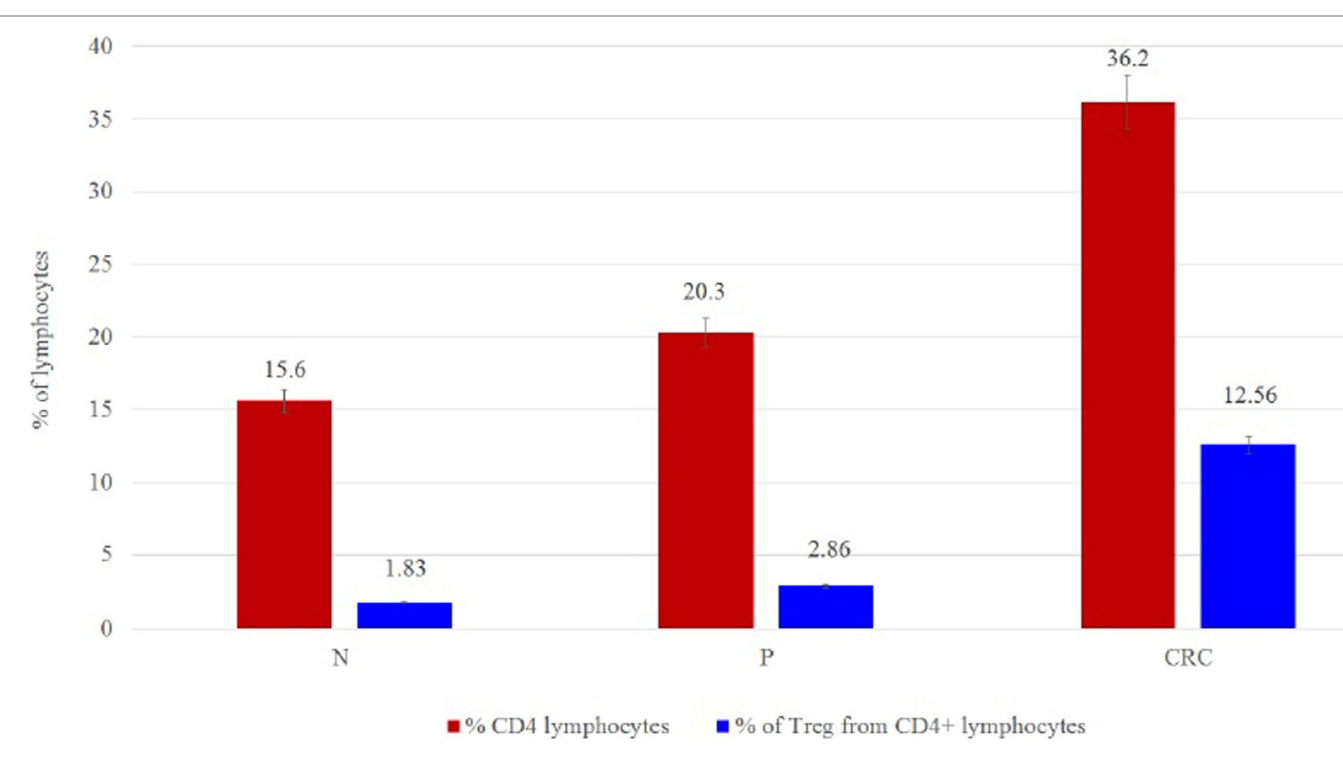

FIGURE 2 | (A) Frequency cell counts and percentage of Tregs per 100,000 lymphocytes for N $(n=15)$, P $(n=15)$, and CRC $(n=15)$ samples. The values are given as mean value \pm SD, $p \leq 0.05$. (B) Percentage of Tregs from lymphocytes.

Treg transcriptome profiles of CRC and P from $\mathrm{N}$ samples, suggesting the three populations to be transcriptionally distinct (Figure 3).
Analysis of the transcriptome using one-way ANOVA, FDR correction $(p<0.01)$, and absolute $\log _{2}$ fold change $(>2$ or $<-2)$ revealed 689 DEGs (330 upregulated; 339 downregulated) in the 


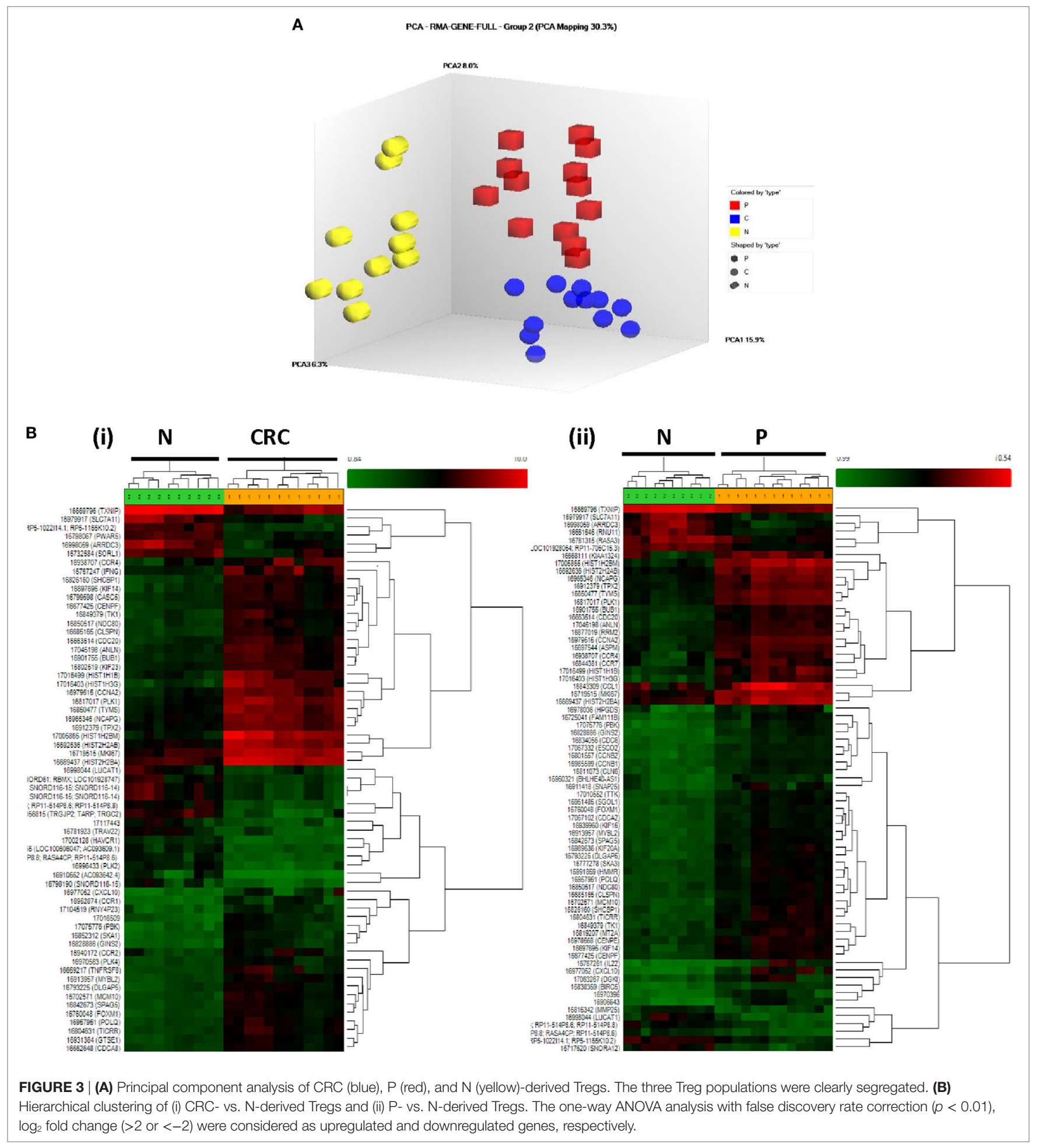

CRC-derived Tregs compared with N-derived Tregs (Data Sheet S1 in Supplementary Material). In the P-derived Tregs, 583 genes were differentially expressed (382 upregulated; 201 downregulated) compared to N-derived Tregs (Data Sheet S2 in Supplementary Material). These DEGs were then grouped using gene ontology biological processes, which identified immune-related genes as the most significant DEG function group in CRC- and P-derived
Tregs (Data Sheets S3 and S4 in Supplementary Material). We then used the Venn diagram to further delineate the DEGs in both groups. N-derived Tregs were used as the baseline (Figure 4).

The overlapped regions show 20 upregulated and 10 downregulated genes in both CRC- and P-derived Tregs. These genes were differentially expressed in both CRC- and P-derived Treg populations (Table 3). In order to distinguish the two populations, 


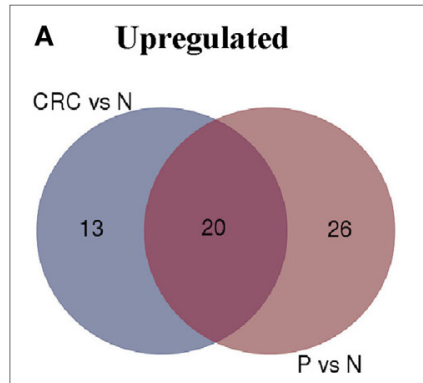

B Downregulated

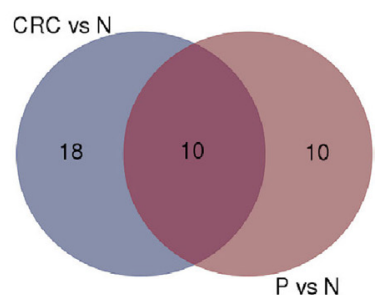

FIGURE 4 | Venn diagram of colorectal carcinoma (CRC) vs.

$\mathbf{N}$ and $\mathbf{P}$ vs. N. (A) Number of upregulated genes between $\mathrm{CRC}$ - and P-derived regulatory $T$ cells (Tregs). (B) Number of downregulated genes in CRC- and P-derived Tregs. Healthy control $(\mathrm{N})$ was used as the baseline.

TABLE 3 | Top 10 gene list of DEGs that were overlapped in CRC- and P-derived Tregs based on Venn diagram analysis.

\begin{tabular}{cccl}
\hline Fold change & $\boldsymbol{p}$-Value & Gene symbol & Description \\
\hline 4.36 & 0.00038 & CCR4 & Chemokine (C-C motif) receptor 4 \\
4.32 & 0.000292 & CXCL10 & Chemokine (C-X-C motif) ligand 10 \\
4.05 & 0.000017 & IFNG & Interferon, gamma \\
4.02 & $6.99 E-09$ & KIF23 & Kinesin family member 23 \\
3.91 & $1.13 E-09$ & CDC6 & Cell division cycle 6 \\
-3.51 & $2.20 E-07$ & TRAJ20 & T cell receptor alpha joining 20 \\
-3.51 & 0.000135 & AREG & Amphiregulin \\
-3.56 & $2.60 E-07$ & YME1L1 & YME1-like 1 ATPase \\
-3.69 & 1.32E-08 & TRAJ1 & T cell receptor alpha joining 1 \\
-5.22 & $4.36 E-09$ & TXNIP & Thioredoxin interacting protein \\
\hline
\end{tabular}

TABLE 4 | Top 10 gene list of DEGs that appeared only in CRC-derived Tregs based on Venn diagram analysis.

\begin{tabular}{|c|c|c|c|}
\hline Fold change & $p$-Value & Gene symbol & Description \\
\hline 5.16 & 0.000005 & CCR1 & Chemokine (C-C motif) receptor 1 \\
\hline 4.21 & 0.000135 & CCR2 & Chemokine (C-C motif) receptor 2 \\
\hline 3.39 & 0.000004 & IFI30 & $\begin{array}{l}\text { Interferon, gamma-inducible } \\
\text { protein } 30\end{array}$ \\
\hline 3.38 & 0.000003 & IL10 & Interleukin 10 \\
\hline 2.66 & 0.000272 & SOCS3 & Suppressor of cytokine signaling 3 \\
\hline-3.49 & $1.01 \mathrm{E}-08$ & TRAJ4 & T cell receptor alpha joining 4 \\
\hline-3.51 & $2.20 \mathrm{E}-07$ & TRAJ20 & T cell receptor alpha joining 20 \\
\hline-3.66 & $6.08 \mathrm{E}-07$ & TRAJ3 & T cell receptor alpha joining 3 \\
\hline-8.51 & 0.000013 & TRAV22 & T cell receptor alpha variable 22 \\
\hline-11.71 & $1.08 \mathrm{E}-08$ & TRGJP2 & T cell receptor gamma joining P2 \\
\hline
\end{tabular}

we focused our analysis on the DEGs that appear exclusively in either CRC- or P-derived Tregs using the N-derived Tregs group as the baseline.

In CRC-derived Tregs, the upregulated genes are those of chemokines that are mostly involved in chemotaxis (CCR1, CCR2) and some interleukins that are important in cytokine-mediated signaling pathway in Treg activation (e.g., IL10, SOCS3). There was consistent downregulation of TCRs in CRC-derived Treg samples (Table 4).

In P-derived Tregs, the DEGs were involved in cell proliferation (e.g., CCNB2 and IL22), binding protein (ANLN), and chemotaxis (CCR7 and CCL1). Significant reduction in expression $(p<0.01)$
TABLE 5 | Top 10 gene list DEGs that appeared only in P-derived Tregs based on Venn diagram analysis.

\begin{tabular}{llcl}
\hline Fold change & $\boldsymbol{p}$-Value & Gene symbol Description \\
\hline 7.32 & 0.000031 & CCR7 & Chemokine (C-C motif) receptor 7 \\
6.76 & 0.000208 & CCL1 & Chemokine (C-C motif) ligand 1 \\
4.41 & $2.15 E-11$ & CCNB2 & Cyclin B2 \\
4.32 & $8.00 E-11$ & ANLN & Anillin, actin binding protein \\
4.11 & 0.000503 & IL22 & Interleukin 22 \\
-2.07 & 0.000087 & GAB2 & GRB2-associated binding protein 2 \\
-2.31 & 0.00002 & TRAJ14 & T cell receptor alpha joining 14 \\
-2.33 & 0.000005 & TNFRSF11A & Tumor necrosis factor receptor \\
& & & superfamily \\
-2.63 & $5.75 E-07$ & IL10RA & Interleukin 10 receptor, alpha \\
-3.65 & 0.000108 & HIST1H2BG & Histone cluster 1 \\
\hline
\end{tabular}

was observed in cell surface receptors (TRAJ 14, IL10RA, and TNFR) (Table 5).

\section{RT-qPCR Analysis of mRNA Expression}

To further validate the gene expression profiles of the Treg populations, a panel of DEGs was chosen from those highlighted in Tables 3-5 and assessed by RT-qPCR. The analysis confirmed a significant increase in the expression of CCR4, CXCL10, CCR1, CCR2, CCR7, and CCL1 genes and a significant decrease in the expression of TRAJ1, TRGJP2, and IL10RA in the CRC- and/ or P-derived Treg populations compared to N-derived Tregs (Figure 5).

\section{DISCUSSION}

$\mathrm{CD}^{+} \mathrm{CD} 25^{+} \mathrm{CD} 127^{\text {low }} \mathrm{FoxP}^{+}$Tregs' frequencies from CRC are higher than $\mathrm{P}$ and $\mathrm{N}$ samples. This appears to be Tregs' characteristic feature in most tumors and compares favorably with previously published data $(31,32)$.

We examined the transcriptome profiles of Tregs derived from CRC, $\mathrm{P}$, and $\mathrm{N}$ samples to uncover specific molecular markers and pathways that might be associated with each group. We found that the DEGs which appeared in both CRC- and P-derived Tregs could represent common genes required for Tregs' suppression of function. It could be that under certain circumstances, some of these genes may trigger immune dysregulation and may also lead to development to polyps or cancer. However, we do not have any clinical data to support this hypothesis.

The common genes identified here include those controlling inflammatory cytokine/chemokine and their receptors. Thus, we observed an upregulation of CCR4 gene expression (both in CRC- and in P-derived Tregs). These findings are consistent with previous studies $(33,34)$. CCR4 is important in mediating Tregs' trafficking to different sites of inflammation. Furthermore, CCR4 is specifically expressed by a subset of most suppressive Tregs but not naive Tregs (35). It could be that the CRC- or P-derived Tregs release the CCR4 ligand and thus are able to attract the Tregs' expressing high levels of CCR4 to the sites of inflammation. Our findings are consistent with previously published data $(33,36)$ that support the important role of CCR4 in mediating Tregs' trafficking to different sites of inflammation. 


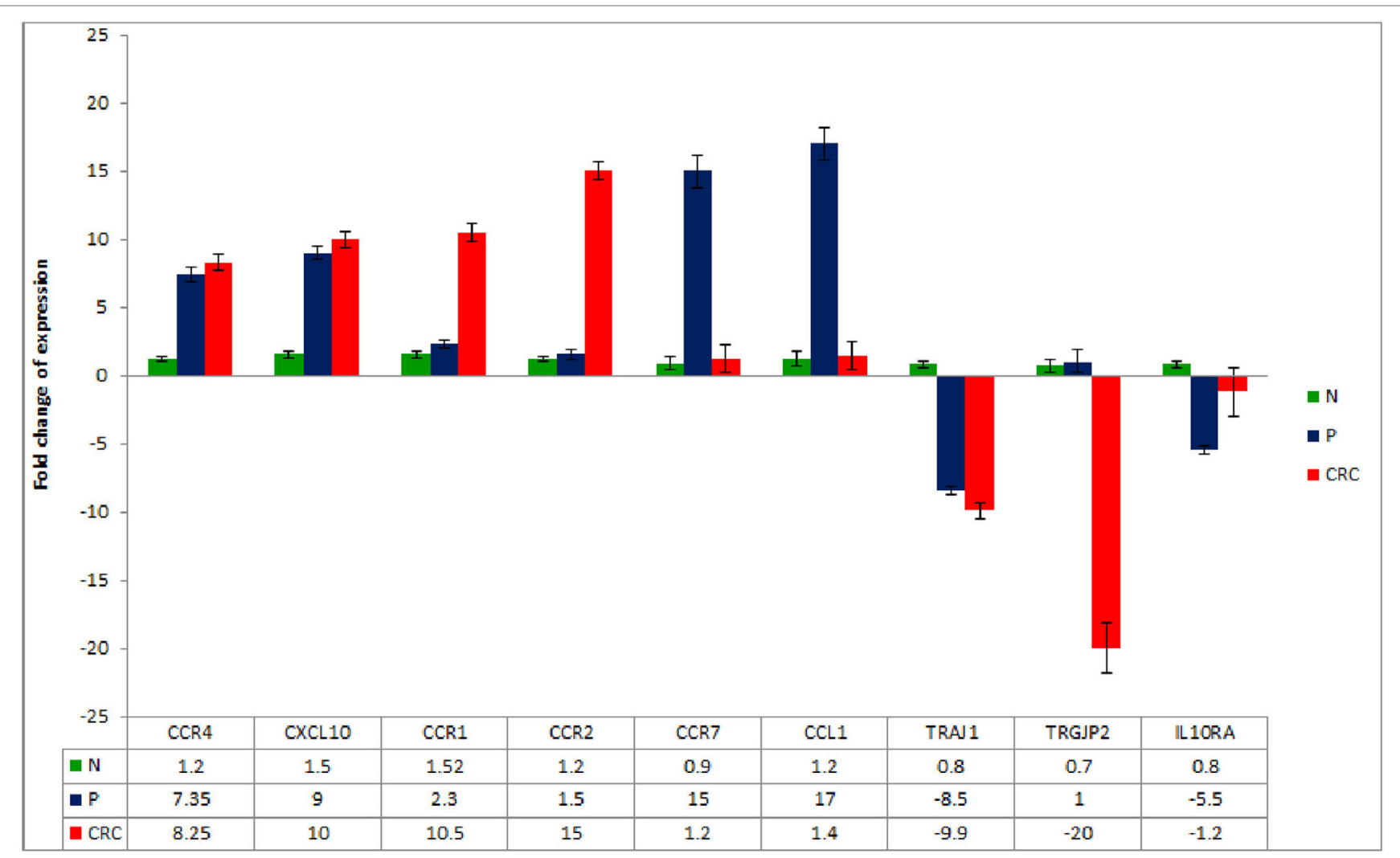

FIGURE 5 | Real-time quantitative reverse transcription PCR analysis of mRNA expression in CRC-, P-, and N-derived Tregs. Data are mean \pm SD, $n=10$ for each of the samples.

We also observed an upregulation of CXCL10 gene that encodes for IFN- $\gamma$-induced protein 10. CXCL10 binds to CXCR3 receptor to promote tumor growth, migration, and invasion of cancer cells in several tumor types (37). CXCR3 is abundantly expressed on other activated effector cells including cytotoxic T-lymphocytes, natural killer cells, and T helper cells. It is possible that the upregulation of CXCL10 in Tregs may affect their homing and migration capacities. This may also influence their interaction with effector cells and may enhance their suppressive function.

Apart from the IFN- $\gamma$ that is produced at the inflammation site, we also observed Tregs and their intrinsic IFN- $\gamma$ gene in both samples (CRC- and P-derived Tregs). This observation is in line with increasing evidence indicating that intrinsic IFN $\gamma$ Tregs play a major role in both inductions of Tregs as well as immunosuppression $(38,39)$. Studies have shown that IFN- $\gamma$ is produced from stable Foxp $3^{+}$Tregs and has an essential immune-regulatory function in preventing experimental graft-versus-host disease (38). IFN- $\gamma$ Tregs develop rapidly during inflammation and represent the first line of Tregs that suppress initial immune responses (39). This supports our findings that Tregs-intrinsic IFN- $\gamma$ production was essential for their immune suppressive function.

We took our analysis further in order to distinguish the genes that are only expressed in CRC- or P-derived Tregs using $\mathrm{N}$-derived Tregs as the baseline. We found that CCR2 was highly expressed on CRC- but not in P-derived Tregs. CCR2 binds the ligand (CCL2) to exert its activity. Tumor environment has been reported to express a high level of CCL2 $(40,41)$. We postulate that CCR2 is important for Tregs migration to the cancer site. This may activate CCL2/CCR2 signaling pathway and is important in promoting tumor growth.

We also observed an overexpression of SOCS3 in Tregs derived from CRC. Overexpression of SOCS3 is correlated with decreased proliferation and suppressive function (42). SOCS3 binds to the Janus kinases directly inhibiting their kinase activity (43). It could be that upregulation of the SOCS3 gene was in response to cytokine stimulation in the CRC environment. It may be that the SOCS proteins produced by Tregs inhibit cytokineinduced signaling pathways in $\mathrm{T}$ effector cells or other immune cells. This is supported by other studies that show a strong correlation of SOCS3 in T cells that inhibit Th1 but promote Th2 development $(44,45)$.

We detected high CCR7 expression in Tregs derived from P compared to CRC population. CCR7 is used by Tregs for homing into lymph nodes (LNs), where they expand upon antigen stimulation and inhibit the generation of antigen-specific $\mathrm{T}$ cells and suppress effector cell responses (46). It is possible that $\mathrm{LN}$ homing is part of their homing mechanism used by all Tregs and its absence may hamper Tregs' localization into functional LN microenvironments.

We also observed high expression of CCL1 in P-derived Tregs. CCL1 is highly differentially regulated in Tregs in the presence 
of IL-6 (47). Neutralization of this chemokine ligand decreased Treg numbers and inhibited Tregs' conversion and suppressive function (47). Increased expression of CCL1 Tregs could be one of the factors that interrupt APCs/T cells interaction. This supports the import function of CCL1 in Treg suppression.

Distinct TCR repertoires are displayed by Treg populations. In our study, we observed the downregulation of TCR in both CRC- and P-derived Tregs. This is in agreement with other studies that described Foxp 3 to potently repress some TCR-induced genes, as well as some genes that are involved in the TCR signaling pathway $(48,49)$. Indeed, the downregulation of TCR in Tregs does not affect their expansion, activity, and function. TCR was largely dispensable for Foxp3 expression, lineage stability, and for high expression of many Treg signature genes (49). This support our data that TCR may not be needed for Tregs' suppression function in CRC and $\mathrm{P}$ patients.

In summary, the present study reports a distinct transcriptomic profile of $\mathrm{CD} 4{ }^{+} \mathrm{CD} 25^{+} \mathrm{CD} 127^{\text {low }} \mathrm{FoxP} 3^{+}$Tregs derived from human CRC, $\mathrm{P}$, and $\mathrm{N}$. We suggest that the molecular signatures identified here may be important for Tregs function in homeostasis and immune suppression. We showed that the transcripts for cytokines, chemokines, and their receptors were highly expressed in CRC- and P-derived Tregs. This suggests their critical role for trafficking and regulating Tregs in CRC and P patients. The study may provide a better understanding of the immunomodulatory nature of Tregs and could, therefore, open up new avenues for immunotherapy.

\section{ETHICS STATEMENT}

Ethics approval was obtained from the UKM Research Ethics Committee (Reference number UKM 1.5.3.5/244/FRGS/2/2013/ $\mathrm{SKK} 01 / \mathrm{UKM} / 03 / 3)$. Participation in this study is voluntary. If the participants agree to take part, then they will be asked to sign the "Informed Consent Form." They will be given a copy of the form and the information sheet on the study. The participant's treatment

\section{REFERENCES}

1. Sakaguchi S, Hori S, Fukui Y, Sasazuki T, Sakaguchi N, Takahashi T. Thymic generation and selection of CD25+CD4+ regulatory T cells: implications of their broad repertoire and high self-reactivity for the maintenance of immunological self-tolerance. Novartis Found Symp (2003) 252:6-16; discussion 23, 106-14. doi:10.1002/0470871628.ch2

2. Chaput N, Louafi S, Bardier A, Charlotte F, Vaillant JC, Ménégaux F, et al. Identification of CD8+CD25+Foxp3+ suppressive T cells in colorectal cancer tissue. Gut (2009) 58(4):520-9. doi:10.1136/gut.2008.158824

3. Endharti AT, Okuno Y, Shi Z, Misawa N, Toyokuni S, Ito M, et al. CD8+CD122+ regulatory T cells (Tregs) and CD4+ Tregs cooperatively prevent and cureCD4+ cell-induced colitis. J Immunol (2011) 186(1):41-52. doi:10.4049/jimmunol. 1000800

4. Zhou J, Ding T, Pan W, Zhu LY, Li L, Zheng L. Increased intratumoral regulatory $\mathrm{T}$ cells are related to intratumoral macrophages and poor prognosis in hepatocellular carcinoma patients. Int J Cancer (2009) 125(7):1640-8. doi:10.1002/ijc. 24556

5. Chen KJ, Lin SZ, Zhou L, Xie HY, Zhou WH, Taki-Eldin A, et al. Selective recruitment of regulatory T cell through CCR6-CCL20 in hepatocellular carcinoma fosters tumor progression and predicts poor prognosis. PLoS One (2011) 6(9):e24671. doi:10.1371/journal.pone.0024671

6. Xu L, Xu W, Qiu S, Xiong S. Enrichment of CCR6+Foxp3+ regulatory T cells in the tumor mass correlates with impaired CD8+ T cell function and poor at the hospital is not affected if they decide not to participate in this study. Should they decide to participate, they can still withdraw from the study without penalty. The data will not be used and will be discarded. The researcher may also remove the participants from the study for a variety of reasons. In this event, the participants will not be penalized or lose their rights as a patient.

\section{AUTHOR CONTRIBUTIONS}

NJ and RJ: conception or design of the work; or NJ, IS: the acquisition, NJ: analysis, or NJ and KT: interpretation of data for the work; and NJ, KT, and RJ: drafted the work or revised it critically for important intellectual content; and NJ, KT, IS, and RJ: final approval of the version to be published, and agreement to be accountable for all aspects of the work in ensuring that questions related to the accuracy or integrity of any part of the work are appropriately investigated and resolved.

\section{ACKNOWLEDGMENTS}

We thank Miss See Hui Shien and Miss Teng Loong Hung for the helpful technical support and advises during flow cytometry cell sorting and microarray analyses respectively.

\section{FUNDING}

This study was supported by the Ministry of Higher Education, Malaysia under the grant FRGS/2/2013/SKK01/UKM/03/3 and GUP-2014-060.

\section{SUPPLEMENTARY MATERIAL}

The Supplementary Material for this article can be found online at http://journal.frontiersin.org/article/10.3389/fimmu.2017.00620/ full\#supplementary-material.

prognosis of breast cancer. Clin Immunol (2010) 135(3):466-75. doi:10.1016/j clim.2010.01.014

7. Liotta F, Gacci M, Frosali F, Querci V, Vittori G, Lapini A, et al. Frequency of regulatory $\mathrm{T}$ cells in peripheral blood and in tumour-infiltrating lymphocytes correlates with poor prognosis in renal cell carcinoma. BJU Int (2011) 107(9):1500-6. doi:10.1111/j.1464-410X.2010.09555.X

8. Shenghui Z, Yixiang H, Jianbo W, Kang Y, Laixi B, Yan Z, et al. Elevated frequencies of $\mathrm{CD}^{+} \mathrm{CD} 25^{+} \mathrm{CD} 127$ lo regulatory $\mathrm{T}$ cells is associated to poor prognosis in patients with acute myeloid leukemia. Int J Cancer (2011) 129(6): 1373-81. doi:10.1002/ijc.25791

9. Salama P, Phillips M, Grieu F, Morris M,Zeps N, Joseph D, et al. Tumor-infiltrating FOXP3+ T regulatory cells show strong prognostic significance in colorectal cancer. J Clin Oncol (2009) 27(2):186-92. doi:10.1200/JCO.2008.18.7229

10. Haas M, Dimmler A, Hohenberger W, Grabenbauer GG, Niedobitek G, Distel LV. Stromal regulatory T-cells are associated with a favorable prognosis in gastric cancer of the cardia. BMC Gastroenterol (2009) 9:65. doi:10.1186/1471-230X-9-65

11. Pretscher D, Distel LV, Grabenbauer GG, Wittlinger $M$, Buettner $M$, Niedobitek G. Distribution of immune cells in head and neck cancer: CD8+ T-cells and CD20+ B-cells in metastatic lymph nodes are associated with favorable outcome in patients with oro- and hypopharyngeal carcinoma. BMC Cancer (2009) 9:292. doi:10.1186/1471-2407-9-292

12. Abbas AK, Benoist C, Bluestone JA, Campbell DJ, Ghosh S, Hori S, et al. Regulatory T cells: recommendations to simplify the nomenclature. Nat Immunol (2013) 14(4):307-8. doi:10.1038/ni.2554 
13. Yu N, Li X, Song W, Li D, Yu D, Zeng X, et al. CD4(+)CD25 (+)CD127 (low/-) T cells: a more specific Treg population in human peripheral blood. Inflammation (2012) 35(6):1773-80. doi:10.1007/s10753-012-9496-8

14. Lim KP, Chun NAL, Ismail SM, Abraham MT, Yusoff MN, Zain RB, et al. $\mathrm{CD} 4{ }^{+} \mathrm{CD} 25^{\text {hi }} \mathrm{CD} 127^{\text {low }}$ Regulatory T Cells Are Increased in Oral Squamous Cell Carcinoma Patients. PLoS One (2014) 9(8):e103975. doi:10.1371/ journal.pone.0103975

15. Shen LS, Wang J, Shen DF, Yuan XL, Dong P, Li MX, et al. CD4(+)CD25(+) CD127(low/-) regulatory T cells express Foxp3 and suppress effector T cell proliferation and contribute to gastric cancers progression. Clin Immunol (2009) 131(1):109-18. doi:10.1016/j.clim.2008.11.010

16. Stewart CA, Metheny H, Iida N, Smith L, Hanson M, Steinhagen F, et al. Interferon-dependent IL-10 production by Tregs limits tumor Th17 inflammation. J Clin Invest (2013) 123(11):4859-74. doi:10.1172/JCI65180

17. Laidlaw BJ, Cui W, Amezquita RA, Gray SM, Guan T, Lu Y, et al. Production of IL-10 by $\mathrm{CD} 4(+)$ regulatory $\mathrm{T}$ cells during the resolution of infection promotes the maturation of memory CD8(+) T cells. Nat Immunol (2015) 16(8):871-9. doi:10.1038/ni.3224

18. Tran DQ. TGF- $\beta$ : the sword, the wand, and the shield of FOXP3(+) regulatory T cells. J Mol Cell Biol (2012) 4(1):29-37. doi:10.1093/jmcb/mjr033

19. Stewart BW, Wild CP. World Cancer Report 2014. Lyon, France: International Agency for Research on Cancer (2014).

20. Omar ZA, Ibrahim Tamin NS. National Cancer Registry Report, Malaysia Cancer Statistics-Data and Figure 2007. Malaysia: Ministry of Health (2011).

21. Hanahan D, Weinberg RA. Hallmarks of cancer: the next generation. Cell (2011) 144(5):646-74. doi:10.1016/j.cell.2011.02.013

22. Hus I, Bojarska-Junak A, Chocholska S, Tomczak W, Woś J, Dmoszyńska A, et al. Th17/IL-17A might play a protective role in chronic lymphocytic leukemia immunity. PLoS One (2013) 8(11):e78091. doi:10.1371/journal.pone.0078091

23. de Bruin EC, van de Velde CJ, van Krieken JH, Marijnen CA, Medema JP. Epithelial human leukocyte antigen-DR expression predicts reduced recurrence rates and prolonged survival in rectal cancer patients. Clin Cancer Res (2008) 14(4):1073-9. doi:10.1158/1078-0432.CCR-07-1597

24. Chaudhuri S, Cariappa A, Tang M, Bell D, Haber DA, Isselbacher KJ, et al. Genetic susceptibility to breast cancer: HLA DQB ${ }^{\star} 03032$ and HLA DRB1 ${ }^{*} 11$ may represent protective alleles. Proc Natl Acad Sci U S A (2000) 97(21):11451-4. doi:10.1073/pnas.97.21.11451

25. Hazewinkel Y, de Wijkerslooth TR, Stoop EM, Bossuyt PM, Biermann K, van de Vijver MJ, et al. Prevalence of serrated polyps and association with synchronous advanced neoplasia in screening colonoscopy. Endoscopy (2014) 46(3):219-24. doi:10.1055/s-0033-1358800

26. Ng SC, Ching JY, Chan VC, Wong MC, Tang R, Wong S, et al. Association between serrated polyps and the risk of synchronous advanced colorectal neoplasia in average-risk individuals. Aliment Pharmacol Ther (2015) 41(1): 108-15. doi:10.1111/apt.13003

27. Urman J, Gomez M, Basterra M, Mercado MD, Montes M, Gómez Dorronsoro $\mathrm{M}$, et al. Serrated polyps and their association with synchronous advanced colorectal neoplasia. Gastroenterol Hepatol (2016) 39(9):574-83. doi:10.1016/j. gastrohep.2015.12.010

28. Li D, Jin C, McCulloch C, Kakar S, Berger BM, Imperiale TF, et al. Association of large serrated polyps with synchronous advanced colorectal neoplasia. Am J Gastroenterol (2009) 104(3):695-702. doi:10.1038/ajg.2008.166

29. Huang CS, Farraye FA, Yang S, O'Brien MJ. The clinical significance of serrated polyps. Am J Gastroenterol (2011) 106(2):229-40; quiz 41. doi:10.1038/ ajg. 2010.429

30. Rex DK, Ahnen DJ, Baron JA, Batts KP, Burke CA, Burt RW, et al. Serrated lesions of the colorectum: review and recommendations from an expert panel. Am J Gastroenterol (2012) 107(9):1315-29; quiz 4, 30. doi:10.1038/ajg.2012.161

31. Shen LS, Wang J, Shen DF, Yuan XL, Dong P, Li MX, et al. $\mathrm{CD} 4+\mathrm{CD} 25+\mathrm{CD} 127$ low/- regulatory $\mathrm{T}$ cells express Foxp3 and suppress effector T cell proliferation and contribute to gastric cancers progression. Clin Immunol (2009) 131(1):109-18. doi:10.1016/j.clim.2008.11.010

32. Betts G, Jones E, Junaid S, El-Shanawany T, Scurr M, Mizen P, et al. Suppression of tumour-specific $\mathrm{CD}^{+} \mathrm{T}$ cells by regulatory $\mathrm{T}$ cells is associated with progression of human colorectal cancer. Gut (2012) 61(8):1163-71. doi:10.1136/ gutjnl-2011-300970

33. Molinaro R, Pecli C, Guilherme RF, Alves-Filho JC, Cunha FQ, Canetti C, et al. CCR 4 controls the suppressive effects of regulatory $\mathrm{T}$ cells on early and late events during severe sepsis. PLoS One (2015) 10(7):e0133227. doi:10.1371/ journal.pone. 0133227
34. Gobert M, Treilleux I, Bendriss-Vermare N, Bachelot T, Goddard-Leon S, Arfi V, et al. Regulatory T cells recruited through CCL22/CCR4 are selectively activated in lymphoid infiltrates surrounding primary breast tumors and lead to an adverse clinical outcome. Cancer Res (2009) 69(5):2000-9. doi:10.1158/0008-5472.CAN-08-2360

35. Sugiyama D, Nishikawa H, Maeda Y, Nishioka M, Tanemura A, Katayama I, et al. Anti-CCR4 mAb selectively depletes effector-type FoxP3+CD4+ regulatory T cells, evoking antitumor immune responses in humans. Proc Natl Acad Sci U S A (2013) 110(44):17945-50. doi:10.1073/pnas.1316796110

36. Ishida T, Ishii T, Inagaki A, Yano H, Komatsu H, Iida S, et al. Specific recruitment of CC chemokine receptor 4-positive regulatory $\mathrm{T}$ cells in Hodgkin lymphoma fosters immune privilege. Cancer Res (2006) 66(11):5716-22. doi:10.1158/0008-5472.CAN-06-0261

37. Lunardi S, Jamieson NB, Lim SY, Griffiths KL, Carvalho-Gaspar M, Al-Assar O, et al. IP-10/CXCL10 induction in human pancreatic cancer stroma influences lymphocytes recruitment and correlates with poor survival. Oncotarget (2014) 5(22):11064-80. doi:10.18632/oncotarget.2519

38. Koenecke C, Lee CW, Thamm K, Föhse L, Schafferus M, Mittrücker HW, et al. IFN- $\gamma$ production by allogeneic Foxp3+ regulatory $\mathrm{T}$ cells is essential for preventing experimental graft-versus-host disease. JImmunol (2012) 189(6):2890-6. doi:10.4049/jimmunol.1200413

39. Daniel V, Wang H, Sadeghi M, Opelz G. Interferon-gamma producing regulatory $\mathrm{T}$ cells as a diagnostic and therapeutic tool in organ transplantation. Int Rev Immunol (2014) 33(3):195-211. doi:10.3109/08830185.2013.845181

40. Chun E, Lavoie S, Michaud M, Gallini CA, Kim J, Soucy G, et al. CCL2 promotes colorectal carcinogenesis by enhancing polymorphonuclear myeloidderived suppressor cell population and function. Cell Rep (2015) 12(2): 244-57. doi:10.1016/j.celrep.2015.06.024

41. Kitamura T, Qian BZ, Soong D, Cassetta L, Noy R, Sugano G, et al. CCL2-induced chemokine cascade promotes breast cancer metastasis by enhancing retention of metastasis-associated macrophages. J Exp Med (2015) 212(7):1043-59. doi:10.1084/jem.20141836

42. Pillemer BB, Xu H, Oriss TB, Qi Z, Ray A. Deficient SOCS3 expression in CD4+CD25+FoxP3+ regulatory $\mathrm{T}$ cells and SOCS3-mediated suppression of Treg function. Eur J Immunol (2007) 37(8):2082-9. doi:10.1002/ eji.200737193

43. Sasaki A, Yasukawa H, Suzuki A, Kamizono S, Syoda T, Kinjyo I, et al. Cytokineinducible $\mathrm{SH} 2$ protein-3 (CIS3/SOCS3) inhibits Janus tyrosine kinase by binding through the $\mathrm{N}$-terminal kinase inhibitory region as well as SH2 domain. Genes Cells (1999) 4(6):339-51. doi:10.1046/j.1365-2443.1999.00263.x

44. Seki Y, Inoue H, Nagata N, Hayashi K, Fukuyama S, Matsumoto K, et al. SOCS-3 regulates onset and maintenance of $\mathrm{T}(\mathrm{H}) 2$-mediated allergic responses. Nat Med (2003) 9(8):1047-54. doi:10.1038/nm896

45. White CA, Nicola NA. SOCS3: an essential physiological inhibitor of signaling by interleukin-6 and G-CSF family cytokines. JAKSTAT (2013) 2(4):e25045. doi:10.4161/jkst.25045

46. Schneider MA, Meingassner JG, Lipp M, Moore HD, Rot A. CCR7 is required for the in vivo function of CD4+ CD25+ regulatory T cells. J Exp Med (2007) 204(4):735-45. doi:10.1084/jem.20061405

47. Hoelzinger DB, Smith SE, Mirza N, Dominguez AL, Manrique SZ, Lustgarten J. Blockade of CCL1 inhibits T regulatory cell suppressive function enhancing tumor immunity without affecting $\mathrm{T}$ effector responses. J Immunol (2010) 184(12):6833-42. doi:10.4049/jimmunol.0904084

48. Ouyang W, Liao W, Luo CT, Yin N, Huse M, Kim MV, et al. Novel Foxo1dependent transcriptional programs control $\mathrm{T}(\mathrm{reg})$ cell function. Nature (2012) 491(7425):554-9. doi:10.1038/nature11581

49. Levine AG, Arvey A, Jin W, Rudensky AY. Continuous requirement for the TCR in regulatory T cell function. Nat Immunol (2014) 15(11):1070-8. doi:10.1038/ni.3004

Conflict of Interest Statement: The authors declare that the research was conducted in the absence of any commercial or financial relationships that could be construed as a potential conflict of interest.

Copyright $\odot 2017$ Johdi, Ait-Tahar, Sagap and Jamal. This is an open-access article distributed under the terms of the Creative Commons Attribution License (CC BY). The use, distribution or reproduction in other forums is permitted, provided the original author(s) or licensor are credited and that the original publication in this journal is cited, in accordance with accepted academic practice. No use, distribution or reproduction is permitted which does not comply with these terms. 